\title{
Optical and scintillation properties of Nd-doped complex garnet
}

Takayuki Yanagida $^{1^{*}}$, Hiroki Sato ${ }^{2}$

${ }^{1}$ Kyushu Institute of Technology, 2-4 Hibikino, Wakamatsu-ku, Kitakyushu 808-0196, Japan

${ }^{2}$ Furukawa Co., Ltd., 1-25-13, Kannondai, Tsukuba, Ibaraki, 305-0856, Japan

\begin{abstract}
Nd 1\% doped complex garnet scintillators were prepared by Furukawa and their optical and scintillation properties were investigated on a comparison with previously reported Nd-doped YAG. Chemical compositions of newly developed complex garnets were $\mathrm{Lu}_{2} \mathrm{Y}_{1} \mathrm{Al}_{5} \mathrm{O}_{12}$, $\mathrm{Lu}_{2} \mathrm{Y}_{1} \mathrm{Ga}_{3} \mathrm{Al}_{2} \mathrm{O}_{12}, \quad \mathrm{Lu}_{2} \mathrm{Gd}_{1} \mathrm{Al}_{5} \mathrm{O}_{12}, \quad \mathrm{Lu}_{2} \mathrm{Gd}_{1} \mathrm{Ga}_{3} \mathrm{Al}_{2} \mathrm{O}_{12}, \mathrm{Gd}_{1} \mathrm{Y}_{2} \mathrm{Al}_{5} \mathrm{O}_{12}, \mathrm{Gd}_{1} \mathrm{Y}_{2} \mathrm{Ga}_{3} \mathrm{Al}_{2} \mathrm{O}_{12}$, and $\mathrm{Gd}_{3} \mathrm{Ga}_{3} \mathrm{Al}_{2} \mathrm{O}_{12}$. They all showed $50-80 \%$ transmittance from ultraviolet to near infrared wavelengths with several absorption bands due to $\mathrm{Gd}^{3+}$ or $\mathrm{Nd}^{3+} 4 \mathrm{f}-4 \mathrm{f}$ transition. In X-ray induced radioluminescence spectra, all samples exhibited intense lines at $310 \mathrm{~nm}$ due to $\mathrm{Gd}^{3+}$ or $400 \mathrm{~nm}$ due to $\mathrm{Nd}^{3+}$ depending on their chemical composition. Among them, the highest scintillation light yield was achieved by $\mathrm{Lu}_{2} \mathrm{Y}_{1} \mathrm{Al}_{5} \mathrm{O}_{12}$. Typical scintillation decay times of them resulted 1.5-3 $\mu$ s. Thermally stimulated glow curve after 1 Gy exposure and X-ray induced afterglow were also investigated.
\end{abstract}

Keywords: Crystal; Scintillation detector; $\mathrm{Nd}^{+}$; Scintillator;

PACS: 07.57.K, 78.60.Y, 78.20

* Corresponding author. Present address: Kyushu Institute of Technology, 2-4 Hibikino, Wakamatsu-ku, Kitakyushu 808-0196, Japan

Tel.: +8193695 6049; fax: +81936956049.

E-mail address: yanagida@lsse.kyutech.ac.jp (Takayuki Yanagida) 


\section{Introduction}

Ionizing radiations such as $\mathrm{X}$ - or gamma-rays have a high penetration power to materials and they have been widely used to many applications such as medical imaging, security, astrophysics, particle physics, and well-logging. In radiation detectors, scintillators which convert the energy of ionizing radiation into a large number of visible/UV photons have played an important role. Up to now, many luminescent materials were investigated on their scintillation properties and among them rare earth doped garnet $\mathrm{X}_{3} \mathrm{Al}_{5} \mathrm{O}_{12}(\mathrm{X}=\mathrm{Y}, \mathrm{Gd}$, or $\mathrm{Lu})$ exhibited good scintillation responses. Ce-doped $\mathrm{Y}_{3} \mathrm{Al}_{5} \mathrm{O}_{12}$ (Ce:YAG) and Pr-doped $\mathrm{Lu}_{3} \mathrm{Al}_{5} \mathrm{O}_{12}(\mathrm{Pr}: \mathrm{LuAG})$ were the most famous ones in this kind of materials.

Recently, some Ce-doped complex garnet materials showed interesting scintillation properties and among them Ce-doped $\mathrm{Gd}_{3} \mathrm{Ga}_{3} \mathrm{Al}_{2} \mathrm{O}_{12}$ (Ce:GAGG) crystal exhibited the best scintillation performance [1-2]. Furthermore, the ceramic counterpart of Ce:GAGG demonstrated quite high scintillation light yield of $70000 \mathrm{ph} / \mathrm{MeV}$ [3]. When we used Robbins model [4], energy transfer efficiency from the host to emission centers have reached a theoretical maximum in this ceramic. Therefore in some aspects, study about Ce-doped complex garnet would saturate experimentally and we have started other material systems or physical properties. Inspired by the pioneering work of scintillation from Nd-doped YAG [5], we recently studied scintillation properties of Nd-doped YAG [6] and LuAG [7], and they exhibited good scintillation responses of medium light yield $(\sim 10000 \mathrm{ph} / \mathrm{MeV})$ and medium decay speed $(\sim 1 \mu \mathrm{s})$. Analogically with Ce:YAG, Nd-doped complex garnet materials, (Y, $\mathrm{Gd}, \mathrm{Lu})_{3}(\mathrm{Ga}, \mathrm{Al})_{5} \mathrm{O}_{12}$, have a large room for study in their scintillation responses. Very recently we investigated scintillation responses of $\left(\mathrm{YGd}_{2}\right)\left(\mathrm{Sc}_{2} \mathrm{Al}_{2} \mathrm{Ga}\right) \mathrm{O}_{12}$ ceramic and their scintillation light yield was not enough [8]. Therefore in this time, we removed Sc from chemical composition for the simplicity. Though in photoluminescence studies, some pioneering works were done for $\mathrm{Gd}_{3}\left(\mathrm{Ga}, \mathrm{Al}_{5}\right)_{12} \mathrm{O}_{12}$ compound [9-11], no report was presented for scintillation. 
In this work, $\mathrm{Nd} 1 \%$ doped, $\mathrm{Lu}_{2} \mathrm{Y}_{1} \mathrm{Al}_{5} \mathrm{O}_{12}, \quad \mathrm{Lu}_{2} \mathrm{Y}_{1} \mathrm{Ga}_{3} \mathrm{Al}_{2} \mathrm{O}_{12}, \quad \mathrm{Lu}_{2} \mathrm{Gd}_{1} \mathrm{Al}_{5} \mathrm{O}_{12}$, $\mathrm{Lu}_{2} \mathrm{Gd}_{1} \mathrm{Ga}_{3} \mathrm{Al}_{2} \mathrm{O}_{12}, \mathrm{Gd}_{1} \mathrm{Y}_{2} \mathrm{Al}_{5} \mathrm{O}_{12}, \mathrm{Gd}_{1} \mathrm{Y}_{2} \mathrm{Ga}_{3} \mathrm{Al}_{2} \mathrm{O}_{12}$, and $\mathrm{Gd}_{3} \mathrm{Ga}_{3} \mathrm{Al}_{2} \mathrm{O}_{12}$ crystal samples were prepared by Furukawa with the micro-pulling down method. Figure 1 demonstrates the picture of samples. Samples were cut to typically $3 \mathrm{~mm} \phi \times 1 \mathrm{mmt}$ and wide surface areas were polished for evaluations. Optical and scintillation properties were investigated and compared with $\mathrm{Nd} 1 \%$ and $2 \%$ doped YAG also prepared by Furukawa. Scintillation properties of Nd:YAG have been already published [6] and used as a reference in this time. In addition to basic scintillation responses, we also investigated thermally stimulated luminescence (TSL) [12] and afterglow [13] properties since afterglow was TSL around room temperature and was one of the important properties of integrated-type detectors like X-ray CT and security systems.

\section{Experimental}

In-line transmittances of all samples were evaluated by using JASCO V670 spectrometer from 190 to $2700 \mathrm{~nm}$ with $1 \mathrm{~nm}$ step. X-ray induced radioluminescence spectra were recorded at room temperature. The X-ray generator (Ourstex Corp.) was used as the excitation source. It equipped $\mathrm{W}$ target and was supplied with $70 \mathrm{kV}$ bias voltage and $1 \mathrm{~mA}$ tube current. The emission spectra were measured using Andor DU-420-BU2 CCD spectrometer in 180-700 nm UV-Vis and DU-492A in 650-1650 $\mathrm{nm}$ in NIR wavelength ranges, respectively. NIR scintillation is potentially applicable for bio imaging applications due to high transparency to human body [14]. These CCD-based detectors were coupled with a monochromator SR163 (Andor, 1200 grooves $/ \mathrm{mm}, 300 \mathrm{~nm}$ blaze wavelength). The scintillation light was fed into spectrometer through a 2 m optical fiber to avoid direct X-ray hit of CCD.

In ${ }^{137} \mathrm{Cs}$ irradiated pulse height measurements, the samples were wrapped with several layers of Teflon tape to collect scintillation photons and were coupled to the photomultiplier 
tube (PMT) R7600-200 (Hamamatsu) with an optical grease (OKEN 6262A). The anode signal of PMT was fed into preamplifier (ORTEC 113), shaping amplifier (CP4467) with 10 $\mu$ s shaping time, and multichannel analyzer (Amptek Pocket MCA). The wavelength sensitivity was from 250 to $650 \mathrm{~nm}$ in this PMT and this condition was the same with previously investigated Nd:YAG [6]. Though NIR scintillation is not accumulated in this setup, such emission has a long decay time (several hundreds $\mu$ s) and general setups for scintillation detector cannot accumulate due to the limitation of the shaping time (generally 10 $\mu \mathrm{s})$.

The scintillation decay times and X-ray induced afterglow were evaluated by our original setups, pulse X-ray excited streak camera system [15] and pulse X-ray equipped afterglow characterization system [16], respectively. Monitoring wavelength in scintillation decay time was $(400 \pm 15 \mathrm{~nm})$ aiming to detect $\mathrm{Nd}^{3+}$ luminescence. The wavelength sensitivity of the afterglow was from 160 to $650 \mathrm{~nm}$ depending on the PMT (R7400) in this system and afterglow profiles were obtained after 100 times data integration. The X-ray exposure time was $2 \mathrm{~ms}$ and the repetition frequency of pulse X-ray was $10 \mathrm{~Hz}$. The time range of this evaluation was $50 \mathrm{~ms}$ and if afterglow continues after $100 \mathrm{~ms}(=10 \mathrm{~Hz})$, signal level before X-ray irradiation becomes worse. This evaluation manner simulates actual operation. Scintillators in actual systems are always irradiated and if worse afterglow scintillators are used, signal levels before X-ray irradiation cannot be negligible. In addition, thermally stimulated luminescence (TSL) was evaluated after 1 Gy X-ray exposure. The setup and experimental procedures for TSL were reported previously [17].

\section{Results and Discussion}

Figure 2 represents in-line transmittance spectra of Nd-doped complex garnet crystals compared with Nd:YAG. All samples showed 50-80\% in-line transmittance from UV to NIR 
wavelengths. In all samples, the $\mathrm{Nd}^{3+} 4 \mathrm{f}^{3}\left({ }^{4} \mathrm{I}_{9 / 2}\right)-4 \mathrm{f}^{2} 5 \mathrm{~d}$ transition was observed around $220 \mathrm{~nm}$. In materials containing $\mathrm{Gd}$ in chemical composition, strong absorption at $275 \mathrm{~nm}$ due to $\mathrm{Gd}^{3+}$ ${ }^{8} \mathrm{~S} \rightarrow{ }^{6} \mathrm{G}_{\mathrm{J}}$ transition was observed. In $\mathrm{Al}$ garnet and $\mathrm{Ga}-\mathrm{Al}$ complex garnete materials, no siginificant differences were observed.

Figure 3 demonstrates X-ray induced radioluminescence spectra from UV to NIR wavelengths. Intense luminescence peaks appeared around $400 \mathrm{~nm}$ due to $\mathrm{Nd}^{3+}{ }^{2} \mathrm{~F}(2)_{5 / 2}->{ }^{4} \mathrm{~F}_{5 / 2}$ and at $1064 \mathrm{~nm}$ due to $\mathrm{Nd}^{3+}{ }^{4} \mathrm{~F}_{3 / 2} \rightarrow{ }^{4} \mathrm{I}_{11 / 2}$ transitions. In $\mathrm{Gd}$ containing materials, $\mathrm{Gd}^{3+}$ luminescence from ${ }^{6} \mathrm{P}_{7 / 2}$ to ${ }^{8} \mathrm{~S}$ transition appeared around $310 \mathrm{~nm}$. Only in $\mathrm{Nd} 1 \%$ doped YAG, broad defect emission was observed around $300 \mathrm{~nm}$. Though we still donot have a quantitative way to compare NIR scintillation, Nd-doped samples exhibited comparable emission intensities with those of $\mathrm{Yb}^{3+}$ doped $\mathrm{Lu}_{2} \mathrm{O}_{3}$ [14]. It must be noted that radioluminescence is advantageous to heavier materials since the stopping power to X-ray via photoelectric absorption is proportinal to $\rho Z_{\text {eff }}^{4}$ where $\rho$ means density and $Z_{\text {eff }}$ effective atomic number.

${ }^{137} \mathrm{Cs}$ irradiated pulse height spectra of present samples compared with Nd-doped YAG are shown in figure 4. As a result, Nd 1\% doped YAG which was previously reported [6] exhibited the highest light yield. Though $\mathrm{Lu}_{2} \mathrm{Y}_{1} \mathrm{Al}_{5} \mathrm{O}_{12}$ and $\mathrm{Lu}_{2} \mathrm{Y}_{1} \mathrm{Ga}_{3} \mathrm{Al}_{2} \mathrm{O}_{12}$ showed a clear photoabsorption peak, other materials did not exhibit such a clear peak. The difference of these two materials with the others was whether they contained Gd in chemical composition or not. Gd admixed garnet materials did not match with $\mathrm{Nd}^{3+}$ doping at least in UV-Visible scintillation possibly due to very slow decay lifetimes of $\mathrm{Gd}^{3+}$. The degradation of light yield of complex garnets than conventional Nd-doped YAG cannot be clearly explained. The simplest explanation is that the crystal quality of complex garnet is worse than Nd-doped YAG due to a complex chemical composition and difficulty in the synthesis. At least it was confirmed in TSL (described later) that complex garnet materials were diffective than $\mathrm{Nd}$ doped YAG. Deduced light yield will be summrized later (table 1). 
Figure 5 demonstrates $\mathrm{X}$-ray induced scintillation decay time profiles of $\mathrm{Nd}^{3+}$-doped complex garnet materials compared with Nd:YAG. Few $\mu$ s component was dominant in this evaluation and the origin of this component was $\mathrm{Nd}^{3+}$. In $\mathrm{Nd} 1 \%$ and $2 \%$ doped YAG, slightly faster component was observed and it would be blamed for the defect emission. In all samples, Ga containing samples showed faster scintillation decay time than that of non-Ga-containing counterparts. In previous report about Pr-doped garnet, Ga doping suppressed the host emission [18] and similar effect could be occurred in the present samples though significant difference was not observed in radioluminescence spectra. Scintillation decay times were deduced by single- or double-exponential assumption and were summrized later.

In Fig. 6, TSL glow curves after 1 Gy X-ray exposure are depicted. Nd 1\% and 2\% doped YAG exhibited the lowest TSL intensity in this temperature range. On the other hand, complex garnet samples exhibited some glow peaks clearly. Generally, TSL intensities are proportional to a number of trap sites. Since complex garnets have a complex chemical composition and difficult to glow with high crystalline quality, they would have more trap site than Nd-doped YAG. It is also generally known that materials with complex chemical compositions are difficult to keep the melt stable and to glow with high crystalline quality, and it was recently proved experimentally in Pr-doped LuAG that the crystalline quality strongly affected the number of defects [19]. Recently, we experimentally proved that optically stimulated luminescence (OSL) and scintillation had a complementary relation as ionizing radiation induced luminescence phenomenon in some material systems [20]. Though OSL and TSL have difference in stimulation sources, before the energy release, processes of energy absorption and storage of ionizing radiation is basically same. Therefore higher TSL intensity of complex garnet than Nd-doped YAG and lower scintillation light yield than Nddoped YAG would be consistent qualitatively. 
Finally, X-ray induced afterglow time profiles of Nd-doped complex garnets are illustrated in figure 7. Afterglow is TSL around room temperature and one of the most important properties for X-ray CT and security systems in airports. Though evaluation manner of afterglow has not standardized, we compared afterglow at time of $20 \mathrm{~ms}$. Table 1 summarizes afterglow at $20 \mathrm{~ms}$ and other scintillation properties. As a result, $\mathrm{Nd} 1$ and $2 \%$ doped YAG exhibited the best value of $0.1-0.3 \%$ of the X-ray exposure (at 2-4 ms). Other samples showed several factors worse afterglow than Nd-doped YAG and these results were consistent with TSL glow curves. $\mathrm{Gd}_{1} \mathrm{Y}_{2} \mathrm{Al}_{5} \mathrm{O}_{12}$ exhibited the worst afterglow property and it was also consistent with TSL because it showed the glow peak at low temperature (= near to room temperature) range. Ga contained samples showed better afterglow property than nonGa-containing counterparts as same as TSL glow curves. Compared with other conventional scintillators for X-ray CT or security systems [16], afterglow properties of Nd-doped garnets were worse. In practical application like CT or security systems, readout phtodetectors are generally $\mathrm{Si}$ photodiode so that NIR scintillation is also accumulated. In such a case, afterglow property of Nd-doped garnet scintillators would be changed.

\section{Conclusion}

Nd $1 \%$ doped $\quad \mathrm{Lu}_{2} \mathrm{Y}_{1} \mathrm{Al}_{5} \mathrm{O}_{12}, \quad \mathrm{Lu}_{2} \mathrm{Y}_{1} \mathrm{Ga}_{3} \mathrm{Al}_{2} \mathrm{O}_{12}, \quad \mathrm{Lu}_{2} \mathrm{Gd}_{1} \mathrm{Al}_{5} \mathrm{O}_{12}, \quad \mathrm{Lu}_{2} \mathrm{Gd}_{1} \mathrm{Ga}_{3} \mathrm{Al}_{2} \mathrm{O}_{12}$, $\mathrm{Gd}_{1} \mathrm{Y}_{2} \mathrm{Al}_{5} \mathrm{O}_{12}, \mathrm{Gd}_{1} \mathrm{Y}_{2} \mathrm{Ga}_{3} \mathrm{Al}_{2} \mathrm{O}_{12}$, and $\mathrm{Gd}_{3} \mathrm{Ga}_{3} \mathrm{Al}_{2} \mathrm{O}_{12}$ were prepared by Furukawa and scintillation properties of them were investigated. They exhibited 50-80\% transparency from UV to NIR wavelengths except some absorption bands due to $\mathrm{Gd}^{3+}$ or $\mathrm{Nd}^{3+} 4 \mathrm{f}-4 \mathrm{f}$ transitions. Intense $\mathrm{Nd}^{3+}$ emission lines around $400 \mathrm{~nm}$ due to $\mathrm{Nd}^{3+}{ }^{2} \mathrm{~F}(2)_{5 / 2} \rightarrow{ }^{4} \mathrm{~F}_{5 / 2}$ and at $1064 \mathrm{~nm}$ due to $\mathrm{Nd}^{3+}{ }^{4} \mathrm{~F}_{3 / 2} \rightarrow{ }^{4} \mathrm{I}_{11 / 2}$ transitions were observed in $\mathrm{X}$-ray induced radioluminescence spectra. Scintillation light yields were several hundreds to $2000 \mathrm{ph} / \mathrm{MeV}$ under ${ }^{137} \mathrm{Cs}$ irradiation with 
typical scintillation decay time of few $\mu$ s. In complex garnet, TSL intensities were higher than Nd-doped YAG and afterglow profiles were also consistent with TSL.

\section{Acknowledgments}

This work was mainly supported by a Grant in Aid for Scientific Research (A)26249147 from the Ministry of Education, Culture, Sports, Science and Technology of the Japanese government (MEXT) and partially by JST A-step. Partial assistance from the Yazaki Memorial Foundation for Science and Technology, Nippon Sheet Glass Foundation for Materials Science and Engineering, Tokuyama Science foundation, Iketani Science and Technology Foundation, Hitachi Metals Materials Science Foundation, Mazda Foundation, JFE $21^{\text {st }}$ century Foundation, and The Asahi Glass Foundation, are also gratefully acknowledged. 


\section{References}

[1] K. Kamada, T. Yanagida, J. Pejchal, M. Nikl, T. Endo, K. Tsutsumi, Y. Fujimoto, A. Fukabori, A. Yoshikawa, J. Phys. D, 44505104 (2011)

[2] K. Kamada , T. Yanagida, J. Pejchal, M. NIkl, T. Endo, K. Tsutsumi, Y. Fujimoto, A. Fukabori, A. Yoshikawa, IEEE Trans. Nucl. Sci., 59 2112-2115 (2012).

[3] T. Yanagida, K. Kamada, Y. Fujimoto, H. Yagi, T. Yanagitani, Opt. Mat., 35 2480$2485(2013)$.

[4] D. J. Robbins, J. Electrochem. Soc. 127, 2694 (1980).

[5] F.A. Danevich_, V.V. Kobychev, S.S. Nagorny, V.I. Tretyak, Nucl. Instr. and Meth. A $541,583(2005)$

[6] T. Yanagida, K. Kamada, Y. Fujimoto, Y. Yokota, A. Yoshikawa, H. Yagi, T. Yanagitani, Nucl. Instrum. Methods A, 631, 54 (2011).

[7] T. Yanagida, Opt. Mater., 351987 (2013).

[8] T. Yanagida, Y. Fujimoto, H. Yagi, T. Yanagitani, M. Sugiyama, A. Yamaji, M. Nikl, Opt. Mat., 35, 788 (2013).

[9] Y. Kuwano, S. Saito, U. Hase, J. Cryst. Growth, 9217 (1988).

[10] Y. Zhi, C. Dong, J. Zhang, Z. Jia, B. Zhang, Y. Zhang, S. Wang, J. He, X. Tao, OPTICS EXPRESS, 18, 7584 (2010).

[11]B. Zhang, J. Yang, J. He, H. Huang, S. Liu, J. Xu, F. Liu,Y. Zhi, X. Tao, OPTICS EXPRESS, 18, 12052 (2010).

[12] S. W.S. McKeever, Thermoluminescence of Solids, Cambridge University Press (1985).

[13]P. A. Rodnyi, Physical Processes in Inorganic Scintillators, CRC Press, Boca Raton, FL, 1997

[14] T. Yanagida, Y. Fujimoto, H. Yagi, T. Yanagitani, Opt. Mater., 361044 (2014). 
[15]T. Yanagida, Y. Fujimoto, A. Yoshikawa, Y. Yokota, K. Kamada, Jan Pejchal, N. Kawaguchi, K. Fukuda, K. Uchiyama, K. Mori, K. Kitano, M. Nikl, Appl. Phys. Exp., $3056202(2010)$.

[16] T. Yanagida, Y. Fujimoto, T. Ito, K. Uchiyama, K. Mori, Appl. Phys. Exp., in press (2014).

[17]T. Yanagida, Y. Fujimoto, N. Kawaguchi, S. Yanagida, J. Ceram. Soc. Jpn., 121989 (2013).

[18] M. Nikl, J. Pejchal, E. Mihokova, J.A.Mares, H. Ogino, A. Yoshikawa, T. Fukuda, A. Vedda, C. D'Ambrosio, Appl. Phys. Lett. 88 141916-1-3 (2006).

[19] A. Yamaji, T. Yanagida, Y. Yokota, K. Kamada, A. Yoshikawa, J. Pejchal, IEEE Trans. Nucl. Sci., 592135 (2012).

[20] T. Yanagida, Y. Fujimoto, K. Watanabe, K. Fukuda, N. Kawaguchi, Y. Miyamoto, H. Nanto, Rad. Meas., in press, DOI: 10.1016/j.radmeas.2014.03.020 (2014). 


\section{Figure Captions}

Figure 1 Photograph of Nd-doped complex garnet. From left to right, $\mathrm{Gd}_{1} \mathrm{Y}_{2} \mathrm{Al}_{5} \mathrm{O}_{12}$, $\mathrm{Gd}_{1} \mathrm{Y}_{2} \mathrm{Ga}_{3} \mathrm{Al}_{2} \mathrm{O}_{12}, \quad \mathrm{Gd}_{3} \mathrm{Ga}_{3} \mathrm{Al}_{2} \mathrm{O}_{12}, \quad \mathrm{Lu}_{2} \mathrm{Y}_{1} \mathrm{Al}_{5} \mathrm{O}_{12}, \quad \mathrm{Lu}_{2} \mathrm{Y}_{1} \mathrm{Ga}_{3} \mathrm{Al}_{2} \mathrm{O}_{12}, \quad \mathrm{Lu}_{2} \mathrm{Gd}_{1} \mathrm{Al}_{5} \mathrm{O}_{12}, \quad$ and $\mathrm{Lu}_{2} \mathrm{Gd}_{1} \mathrm{Ga}_{3} \mathrm{Al}_{2} \mathrm{O}_{12}$.

Figure 2 In-line transmittance spectra of (a) $\mathrm{Lu}_{2} \mathrm{Y}_{1} \mathrm{Al}_{5} \mathrm{O}_{12}, \mathrm{Lu}_{2} \mathrm{Y}_{1} \mathrm{Ga}_{3} \mathrm{Al}_{2} \mathrm{O}_{12}, \mathrm{Lu}_{2} \mathrm{Gd}_{1} \mathrm{Al}_{5} \mathrm{O}_{12}$, and $\mathrm{Lu}_{2} \mathrm{Gd}_{1} \mathrm{Ga}_{3} \mathrm{Al}_{2} \mathrm{O}_{12}$, and (b) $\mathrm{Gd}_{1} \mathrm{Y}_{2} \mathrm{Al}_{5} \mathrm{O}_{12}, \mathrm{Gd}_{1} \mathrm{Y}_{2} \mathrm{Ga}_{3} \mathrm{Al}_{2} \mathrm{O}_{12}, \mathrm{Gd}_{3} \mathrm{Ga}_{3} \mathrm{Al}_{2} \mathrm{O}_{12}, \mathrm{Nd} 1 \% \mathrm{YAG}$, and Nd 2\% YAG.

Figure 3 X-ray induced radioluminescence spectra of Nd-doped complex garnet in UV-Vis (a), (c) and NIR (b), (d) wavelengths.

Figure $4{ }^{137} \mathrm{Cs}$ induced pulse height spectra of Nd-doped complex garnet.

Figure $5 \mathrm{X}$-ray induced scintillation decay time profiles of (a) $\mathrm{Lu}_{2} \mathrm{Y}_{1} \mathrm{Al}_{5} \mathrm{O}_{12}, \mathrm{Lu}_{2} \mathrm{Y}_{1} \mathrm{Ga}_{3} \mathrm{Al}_{2} \mathrm{O}_{12}$, $\mathrm{Lu}_{2} \mathrm{Gd}_{1} \mathrm{Al}_{5} \mathrm{O}_{12}$, and $\mathrm{Lu}_{2} \mathrm{Gd}_{1} \mathrm{Ga}_{3} \mathrm{Al}_{2} \mathrm{O}_{12}$, and (b) $\mathrm{Gd}_{1} \mathrm{Y}_{2} \mathrm{Al}_{5} \mathrm{O}_{12}, \mathrm{Gd}_{1} \mathrm{Y}_{2} \mathrm{Ga}_{3} \mathrm{Al}_{2} \mathrm{O}_{12}, \mathrm{Gd}_{3} \mathrm{Ga}_{3} \mathrm{Al}_{2} \mathrm{O}_{12}$, Nd 1\% YAG, and Nd 2\% YAG.

Figure 6 TSL glow curves of Nd-doped complex garnet scintillators after 1 Gy X-ray exposure.

Figure $7 \mathrm{X}$-ray induced afterglow time profiles of (a) $\mathrm{Lu}_{2} \mathrm{Y}_{1} \mathrm{Al}_{5} \mathrm{O}_{12}, \mathrm{Lu}_{2} \mathrm{Y}_{1} \mathrm{Ga}_{3} \mathrm{Al}_{2} \mathrm{O}_{12}$, $\mathrm{Lu}_{2} \mathrm{Gd}_{1} \mathrm{Al}_{5} \mathrm{O}_{12}$, and $\mathrm{Lu}_{2} \mathrm{Gd}_{1} \mathrm{Ga}_{3} \mathrm{Al}_{2} \mathrm{O}_{12}$, and (b) $\mathrm{Gd}_{1} \mathrm{Y}_{2} \mathrm{Al}_{5} \mathrm{O}_{12}, \mathrm{Gd}_{1} \mathrm{Y}_{2} \mathrm{Ga}_{3} \mathrm{Al}_{2} \mathrm{O}_{12}, \mathrm{Gd}_{3} \mathrm{Ga}_{3} \mathrm{Al}_{2} \mathrm{O}_{12}$, Nd $1 \%$ YAG, and Nd 2\% YAG. 
Table 1 Scintillation properties of complex garnet compared with Nd:YAG. 
Figure2

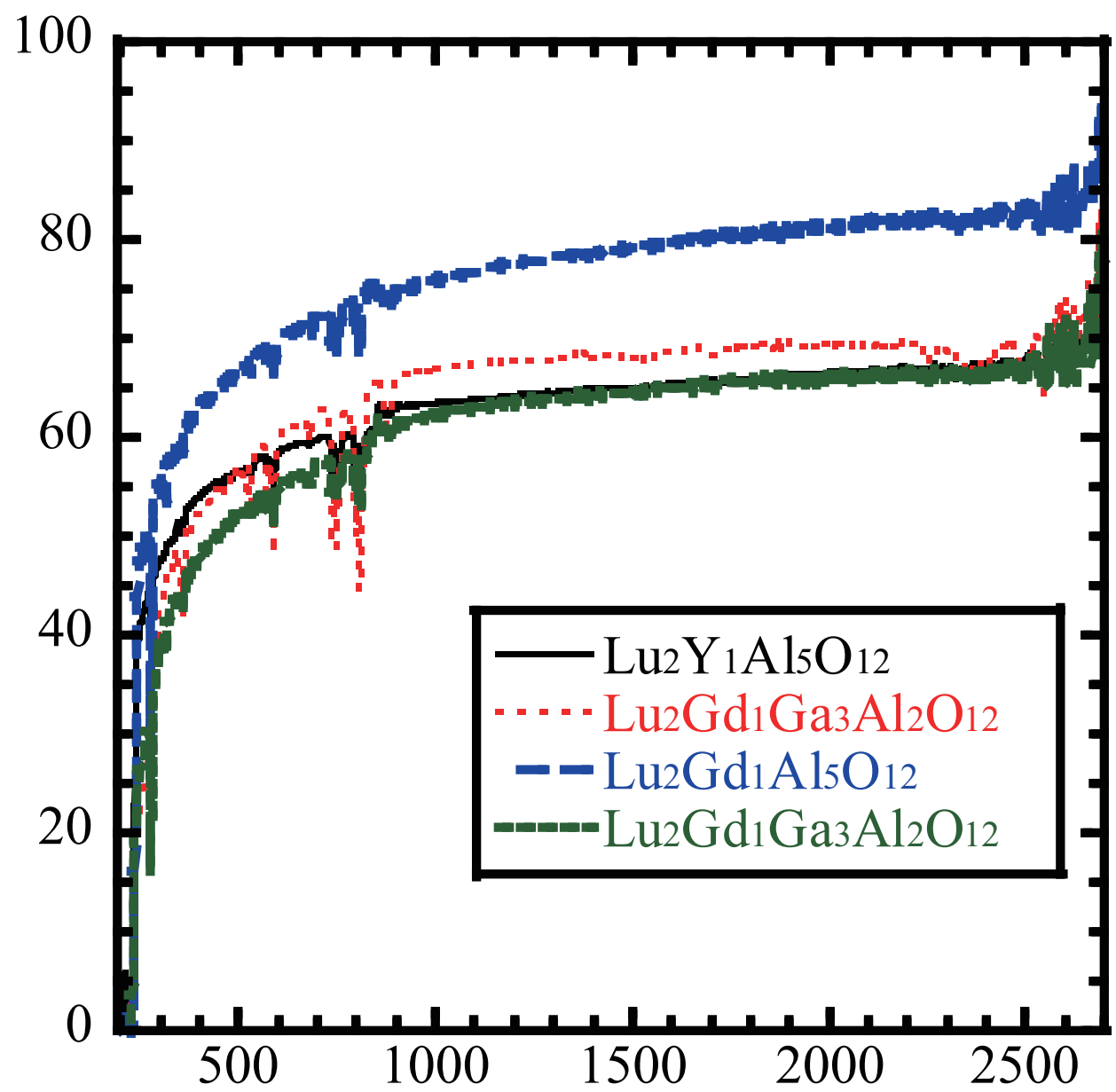

Wavelength (nm)

(b)

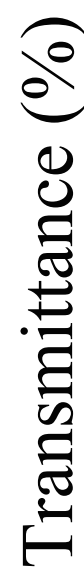

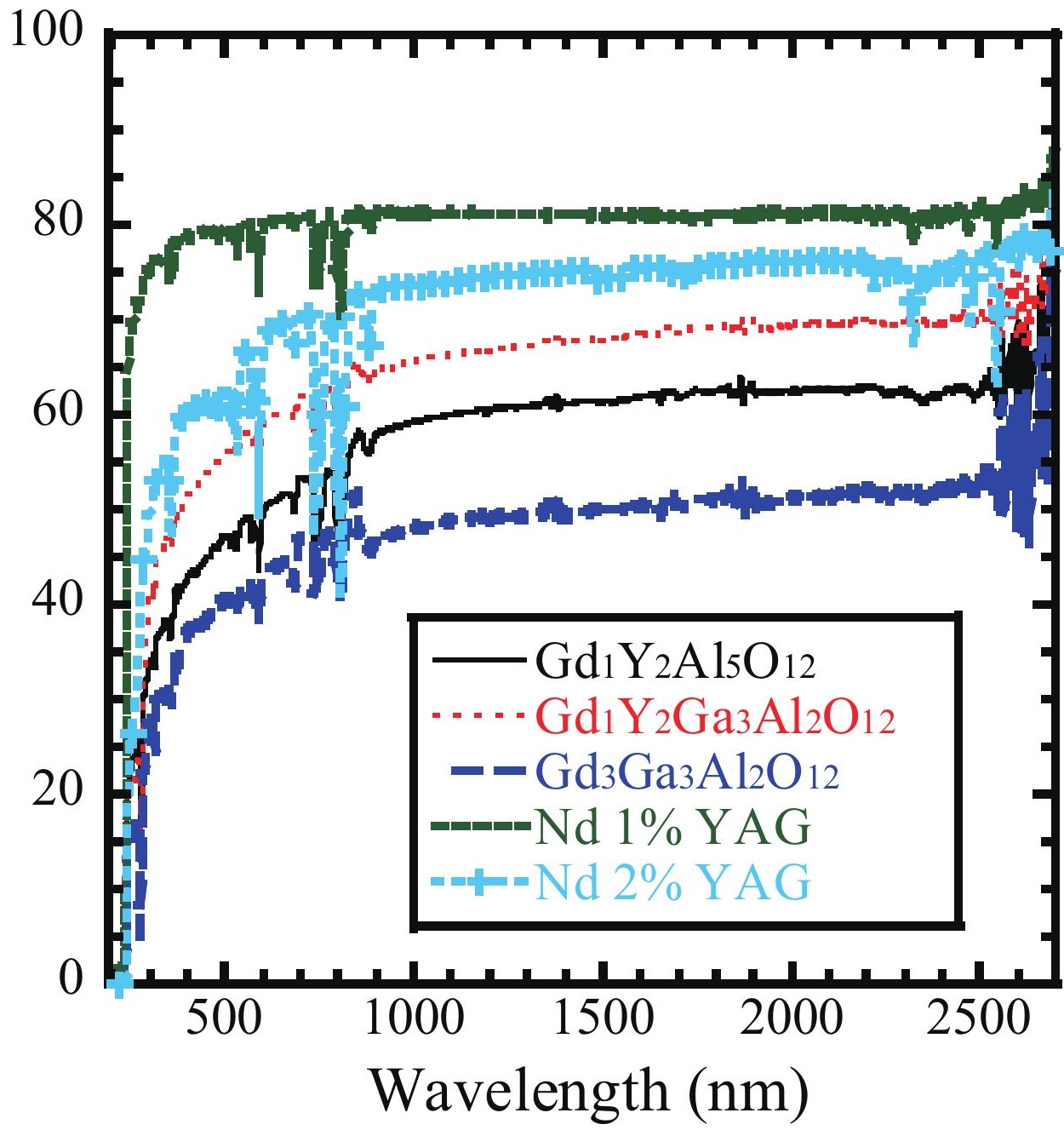



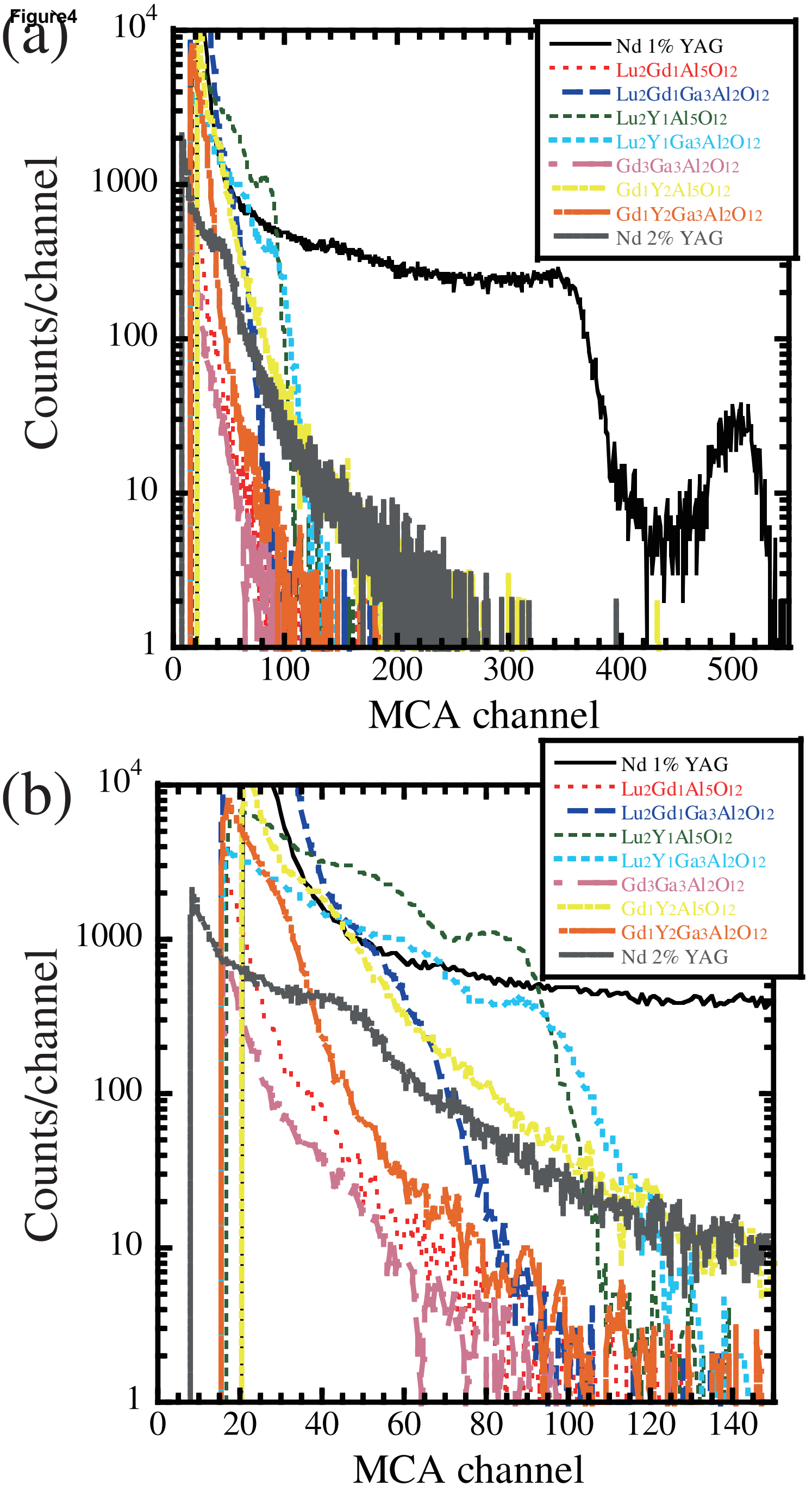


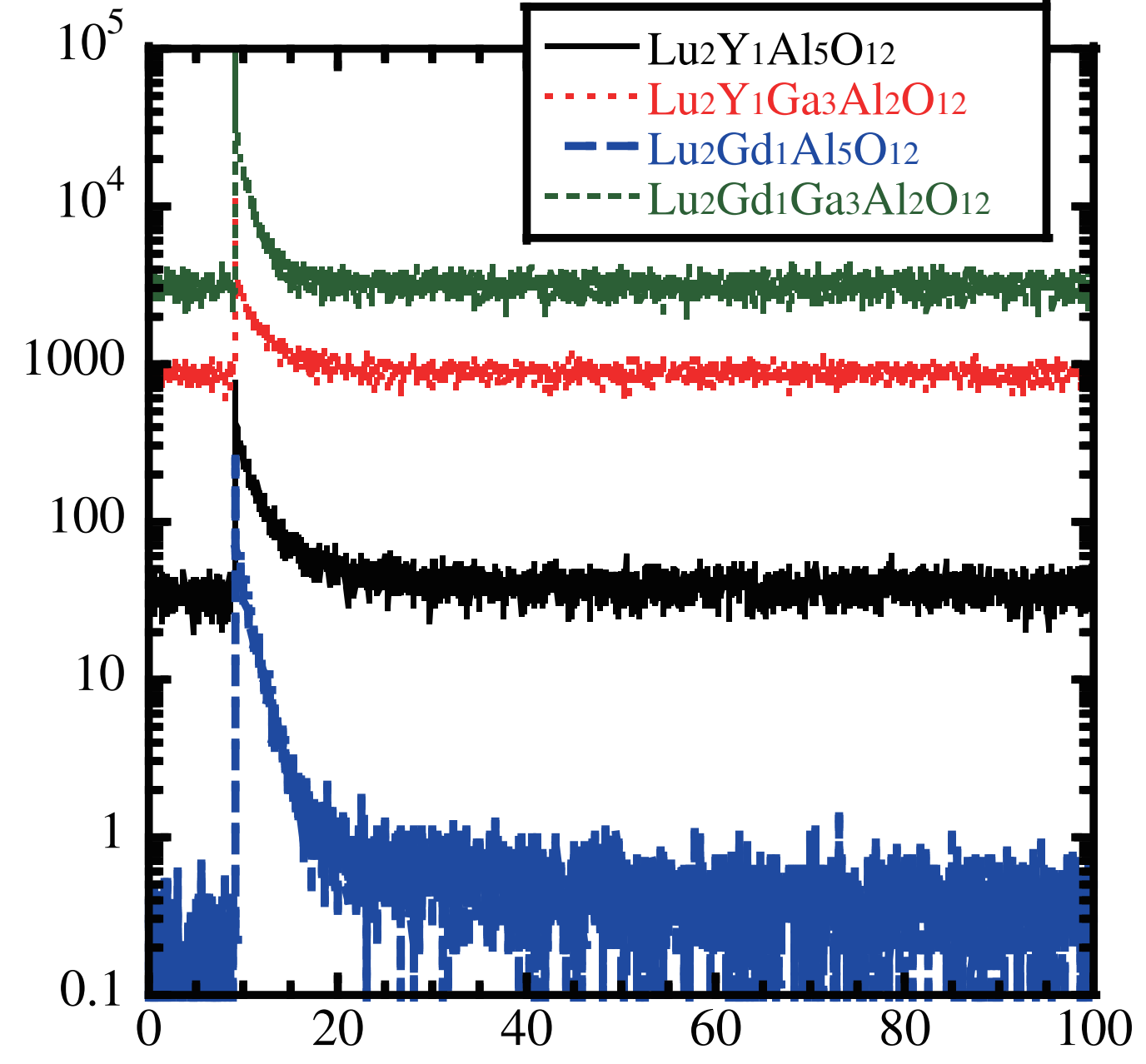

10

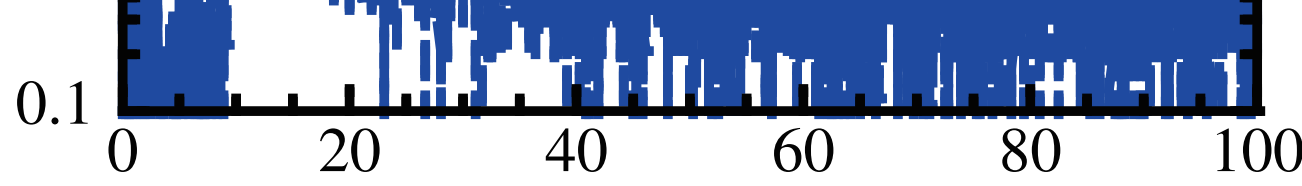

$+4+1$

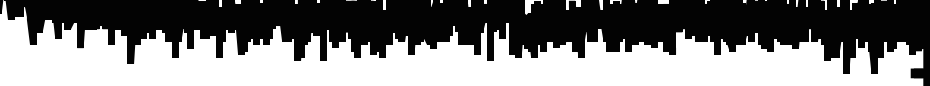

1

1

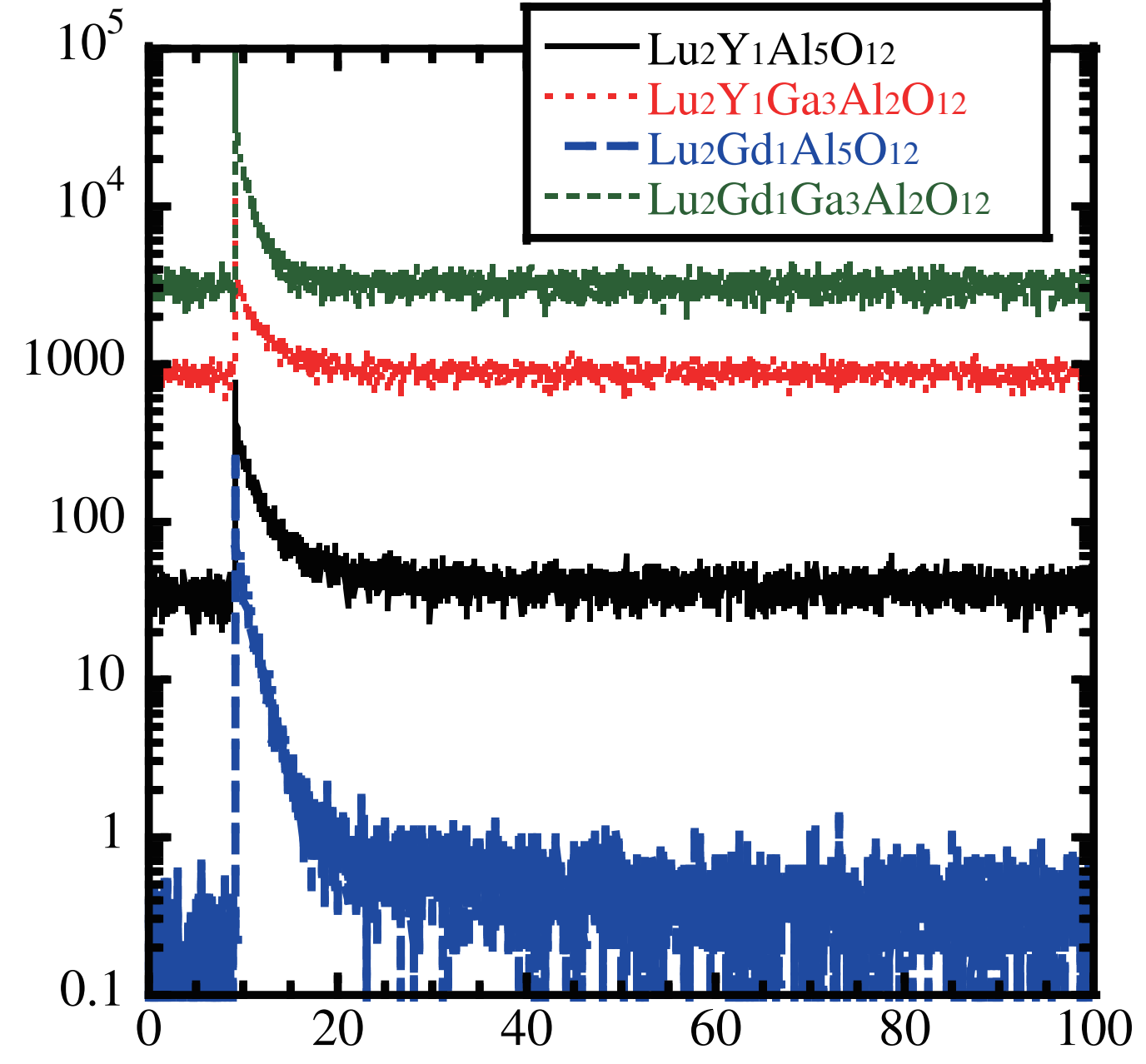

(b)

Time $(\mu s)$

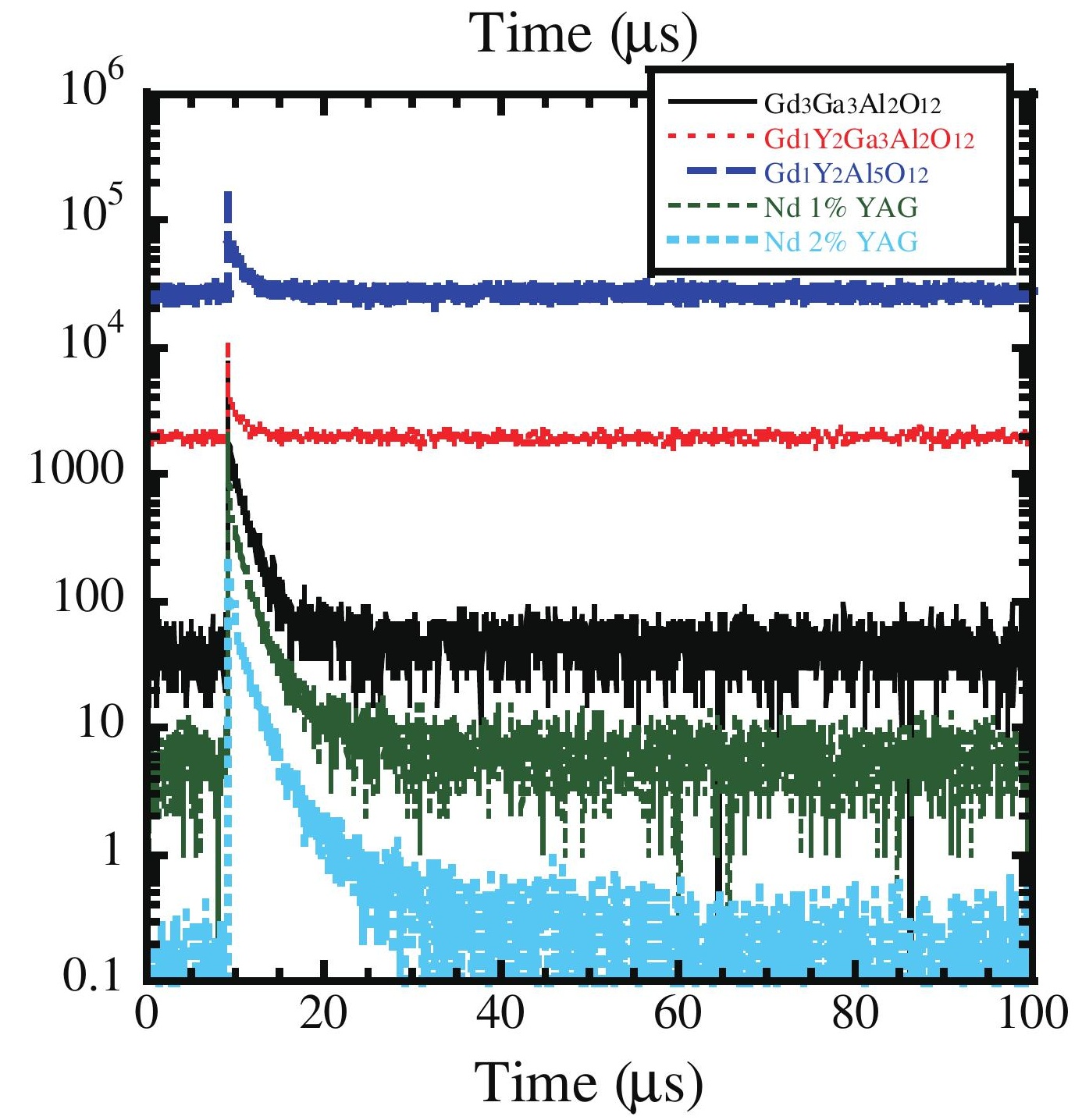




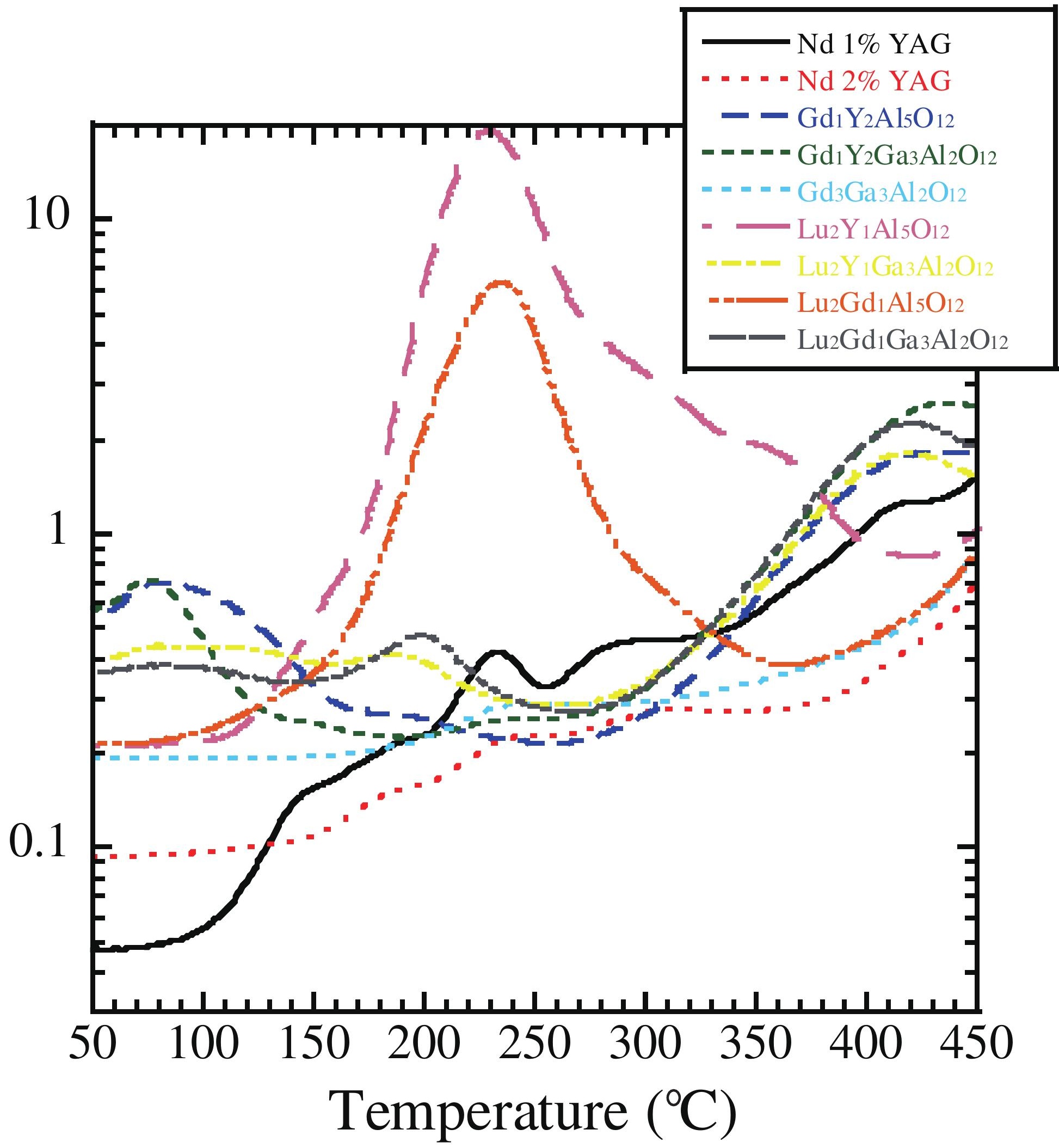




\begin{tabular}{|c|c|c|c|c|}
\hline & $\begin{array}{c}\text { Light yield } \\
(\mathrm{ph} / \mathrm{MeV})\end{array}$ & $\begin{array}{c}\text { Decay time } \\
(\mu \mathrm{s})\end{array}$ & $\begin{array}{c}\text { TL glow peak } \\
(\text { degree } \mathrm{C})\end{array}$ & $\begin{array}{c}\text { Afterglow (\% } \\
\text { at 20 ms })\end{array}$ \\
\hline $\mathrm{Lu}_{2} \mathrm{Y}_{1} \mathrm{Al}_{5} \mathrm{O}_{12}$ & 2000 & 2.63 & 230 & 1.6 \\
\hline $\mathrm{Lu}_{2} \mathrm{Y}_{1} \mathrm{Ga}_{3} \mathrm{Al}_{2} \mathrm{O}_{12}$ & 2200 & 2.25 & 100,180 & 0.7 \\
\hline $\mathrm{Lu}_{2} \mathrm{Gd}_{1} \mathrm{Al}_{5} \mathrm{O}_{12}$ & 1000 & 1.71 & 230 & 1 \\
\hline $\mathrm{Lu}_{2} \mathrm{Gd}_{1} \mathrm{Ga}_{3} \mathrm{Al}_{2} \mathrm{O}_{12}$ & $<400$ & 1.52 & $75,200,400$ & 0.9 \\
\hline $\mathrm{Gd}_{1} \mathrm{Y}_{2} \mathrm{Al}_{5} \mathrm{O}_{12}$ & 800 & 1.1 & 75,400 & 2.4 \\
\hline $\mathrm{Gd}_{1} \mathrm{Y}_{2} \mathrm{Ga}_{3} \mathrm{Al}_{2} \mathrm{O}_{12}$ & 600 & 0.93 & 75,400 & 0.9 \\
\hline $\mathrm{Gd}_{3} \mathrm{Ga}_{3} \mathrm{Al}_{2} \mathrm{O}_{12}$ & $<400$ & 1.71 & 250 & 1.3 \\
\hline $\mathrm{Nd} 1 \% \mathrm{YAG}$ & 11000 & $0.79+3.18$ & 230,280 & 0.3 \\
\hline $\mathrm{Nd} 2 \% \mathrm{YAG}$ & 900 & $0.48+2.62$ & 230,280 & 0.1 \\
\hline
\end{tabular}

